\title{
FIT OF LASER SINTERED METAL RESTORATIONS: A SYSTEMATIC REVIEW
}

\author{
Amir S. Azer* and Heidar Shahin*
}

\begin{abstract}
Objective: The aim of this study is to review all the published in vitro research on the fit of laser sintered metal copings compared to other fabrication techniques.

Materials and Methods: A comprehensive electronic search was performed through Google Scholar to combine the following key words: '3D printing', 'rapid prototyping', 'laser sintering', 'direct metal laser sintering', 'laser melting', 'metal coping', 'cobalt chromium coping', 'metal crown', 'cobalt chromium crown', 'internal fit' and 'marginal fit'. The search was limited to articles written in English. In addition, a manual search was also conducted through articles and reference lists retrieved from the electronic search and peer reviewed journals.
\end{abstract}

Results: A total of 284 articles were retrieved and only 17 met the specified inclusion criteria for the review. The selected articles had assessed marginal and/or internal fit of laser sintered metal copings against other fabrication techniques.

Conclusions: Laser sintered metal copings have a good marginal and internal fit within the clinically acceptable range suggested in the literature. Laser sintering procedure provides an efficient and rapid method for digitally designing and manufacturing complex metal structures for crowns and FPDs.

KEY WORDS: 3D printing- laser sintering- metal coping- internal fit - marginal fit.

\section{INTRODUCTION}

Metal-ceramic restorations are still extensively used as they showed excellent clinical performance and mechanical properties throughout the years. Their cost is relatively low compared to metal- free restorations and have simpler cementation procedures, in addition to their role in natural reproduction of lost dentition. In the fabrication of cast metal restorations, the lost wax casting technique is one of the most used methods. However, in recent

* Lecturer of Fixed Prosthodontics, Conservative Dentistry Department, Faculty of Dentistry, Alexandria University, Alexandria, Egypt. 
years, new fabrication techniques, which are more efficient, began to be used instead of conventional ones..$^{(1,2)}$

Along with the CAD/CAM milling, a paradigm shift in the procedure for fabricating the metal coping has come into life with the introduction of 3D printing technology. 3D printing can be used for the fabrication of metal structures either indirectly by printing in burn-out resins or waxes for a lostwax process, or directly in metal alloys. ${ }^{(3)}$ The direct 3D printing of metal alloys - also known as laser sintering of metal alloys - allows the elimination of a major drawback of the lost wax technique: the casting shrinkage, easy fabrication of complex shapes, operation of an automatic system, and short working time due to elimination of the lost wax technique long procedures ${ }^{(4)}$. Because laser sintering is considered a new manufacturing technique, it requires extensive evaluation before it might be used to produce prostheses for clinical use.

The accurate fit is considered mandatory for a fixed restoration to achieve acceptable longevity. (5-7) A poor fit is responsible for $10 \%$ of prosthetic failures ${ }^{(8)}$. The fit of any restoration is determined by its marginal and internal fit. The ideal internal or marginal adaptation will result in minimal plaque accumulation and bone loss, less gingival irritation, less cement dissolution, less recurrent caries and less marginal discoloration. The purpose of this systematic review is to review the in vitro research on the fit of laser sintered metal copings compared to other fabrication techniques.

\section{MATERIALS AND METHODS}

This systematic review was conducted in accordance with the PRISMA statement ${ }^{(9)}$. The PRISMA flowchart summarizing the systematic review process is shown in figure 1 .

\section{Search strategy and selection criteria}

The purpose of the search was to obtain all the articles on the fit of laser sintered metal copings following the inclusion criteria: Articles published in English, In-vitro studies, using one of 3D printing/ additive manufacturing/laser sintering techniques in the direct construction of metal copings/crowns/ FPDs and testing the internal and/or marginal fit accuracy. Electronic search was performed in the Google Scholar database using the following keywords: "3D printing" OR "rapid prototyping" OR "laser sintering " OR "direct metal laser sintering" OR "laser melting" AND "metal coping" OR "cobalt chromium coping" OR "metal crown" OR "cobalt chromium crown" AND "internal fit" OR "marginal fit". No publication year limit was used. The electronic search was supplemented by manual searching. In addition, the references of the selected articles were reviewed for possible inclusion.

\section{Study selection and data extraction}

Titles and abstracts of all studies identified in the electronic search were screened. Studies that did not meet the predefined inclusion criteria were excluded. All remaining studies were subjected to a full text review. Studies falling within the inclusion criteria were assessed and data were extracted. The primary outcome measures analyzed included the marginal and internal fit accuracy of crowns or FPDs constructed by additive manufacturing techniques compared to other techniques.

\section{RESULTS}

\section{Study search}

Initial database searching resulted in 284 studies, 1 additional study was identified through manual hand search. After duplicates removal, excluded studies from title and abstract, and assessing full text studies for eligibility, 17 studies $^{(1,2,4,8,10-22)}$ were included in this systematic review. Table 1 shows a summary of the studies included in this systematic review. 


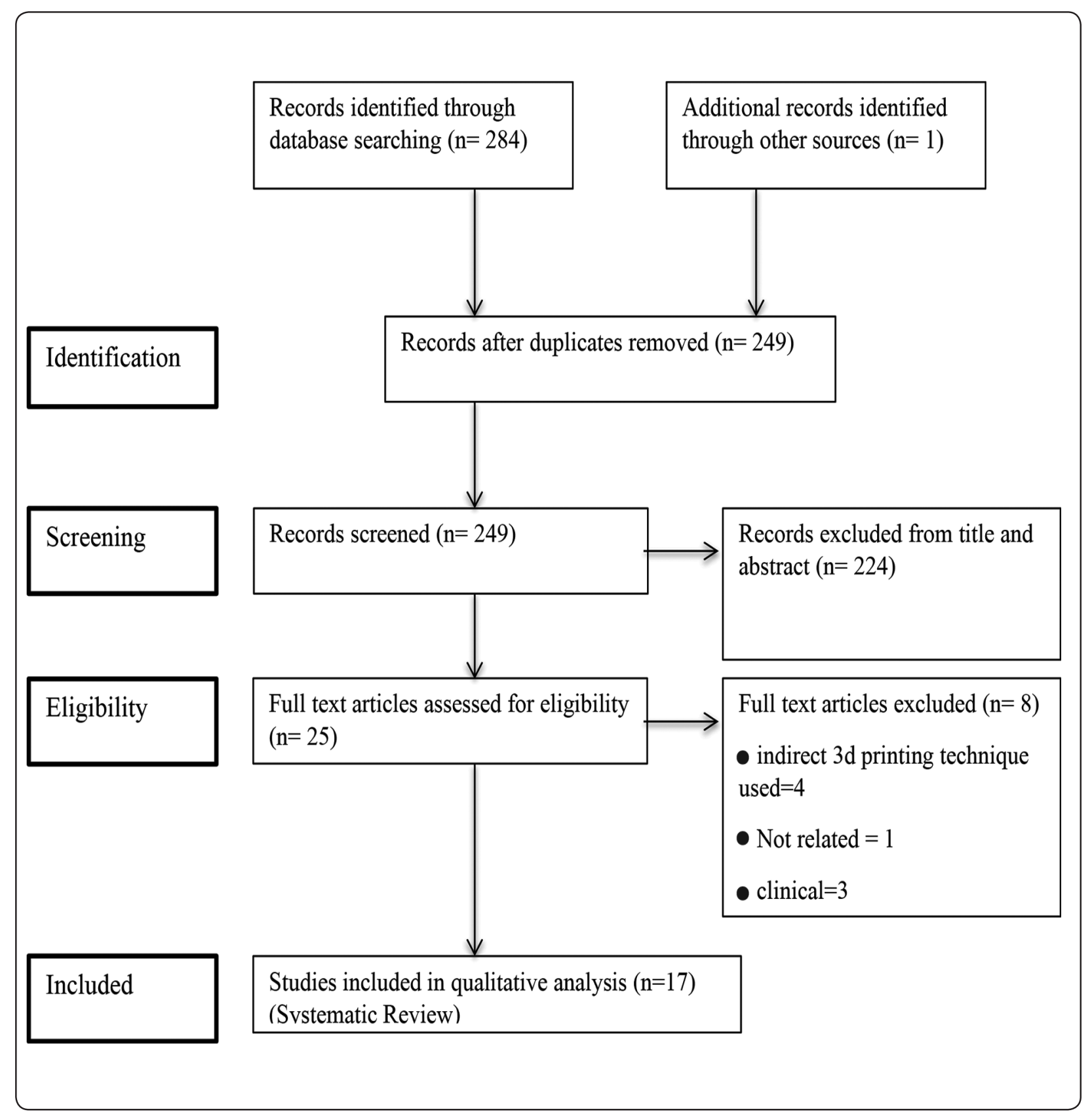

Fig. (1) : PRISMA flow chart of the systematic review 


\section{Description of studies}

Of the included 17 articles, 6 articles ${ }^{(4,8,13,18,20,22)}$ $(35.3 \%)$ only assessed the marginal fit accuracy, one article ${ }^{(10)}(5.9 \%)$ only assessed the internal fit accuracy and 10 articles $^{(1,2,11,12,14-17,19,21)}(58.84 \%)$ assessed both the marginal and internal fit accuracy. 13 articles $^{(1,2,4,10,12,14-18,20-22)}(76.5 \%)$ used single crown frameworks, 3 articles ${ }^{(11,13,19)}(17.6 \%)$ used fixed-partial-denture frameworks and only one $\operatorname{article}^{(8)}(5.9 \%)$ used both single crown and fixedpartial-denture frameworks for the fit accuracy assessment.

Since this was the purpose of the systematic review, all the articles investigated the fit accuracy of laser sintered metal frameworks. Cobalt Chromium (Co-Cr) was the material used in all the articles (100\%) for laser sintering. 14 of them ${ }^{(1,2,8,10,11,13-15,17-22)}(82.4 \%)$ used the direct metal laser sintering technique (DMLS) that is also known as selective laser melting (SLM) and 3 of them ${ }^{(4,12,16)}$ $(17.6 \%)$ used the selective laser sintering technique (SLS).

Different fabrication techniques were used for the comparison of the fit accuracy with the laser sintering of metal frameworks. The most common one was the lost wax method whether it used the conventional manual wax pattern ${ }^{(1,4,8,10-14,16-22)}$, wax pattern milling using CAD/CAM technology $(1,2,11,15,17)$ or $3 \mathrm{D}$ printing of wax/resin pattern ${ }^{(1,14)}$. Among other techniques, milling of $\mathrm{Co}-\mathrm{Cr}$ metal frameworks using CAD/CAM technology was used in 7 articles $^{(1,2,11,16,17,19,21)}$. Only one article ${ }^{(8)}$ used CAD/CAM zirconia milling.

The selected articles show significant heterogeneity in terms of experimental methodology and sample size. The approaches used for the marginal and internal fit assessment were:

- Silicone replica $\operatorname{approach}^{(1,12,13,18-21)}$. Lowviscosity silicone impression material is injected in the fitting surface of the restoration. This step is followed by seating the restoration on the preparation. After the removal of metal framework, the thin layer of the low-viscosity material is stabilized by higher viscosity impression material to facilitate the handling. The silicone replica can then be sectioned and magnified.

- 3D replica approach ${ }^{(12,16)}$. The preparation is scanned with a dental scanner. After scanning, low-viscosity silicone impression material is injected in the fitting surface of the restoration in a manner similar to the conventional silicone replica technique and the restoration is seated on the preparation. After the removal of metal framework, the silicone impression material is kept on the preparation while a digital replica is made using a dental scanner. To 3-dimensionally measure the gap between the digital replicas, point cloud data are obtained from the digital replica files by using a dedicated program.

- Internal microscopic examination after cementation and sectioning of the specimen ${ }^{(2,8,10,11,14,15,17)}$. The metal framework is cemented to its corresponding preparation. After it sets, the metal framework along with the preparation are sectioned longitudinally and then examined microscopically. Some articles add colour to the cement before cementation ${ }^{(11,15,17)}$ to be more visible under the microscope.

- External microscopic examination of the marginal area. It can be either done without cementation $^{(2,4)}$ or after using cement ${ }^{(14)}$ or silicone pressure indicating paste ${ }^{(22)}$.

- Silicone impression weighing $\operatorname{approach}^{(2,10)}$. Low-viscosity silicone impression material is injected in the fitting surface of the restoration that is then seated on the preparation. After the removal of metal framework, the thin layer of the low-viscosity material is removed and weighed using an analytical balance.

- Direct-sight approach ${ }^{(19)}$. The marginal fit is evaluated with direct-sight approach at a 90-degree angle on the tooth surface. Preparation is colored with a red marker so that the preparation border can be clearly seen. 


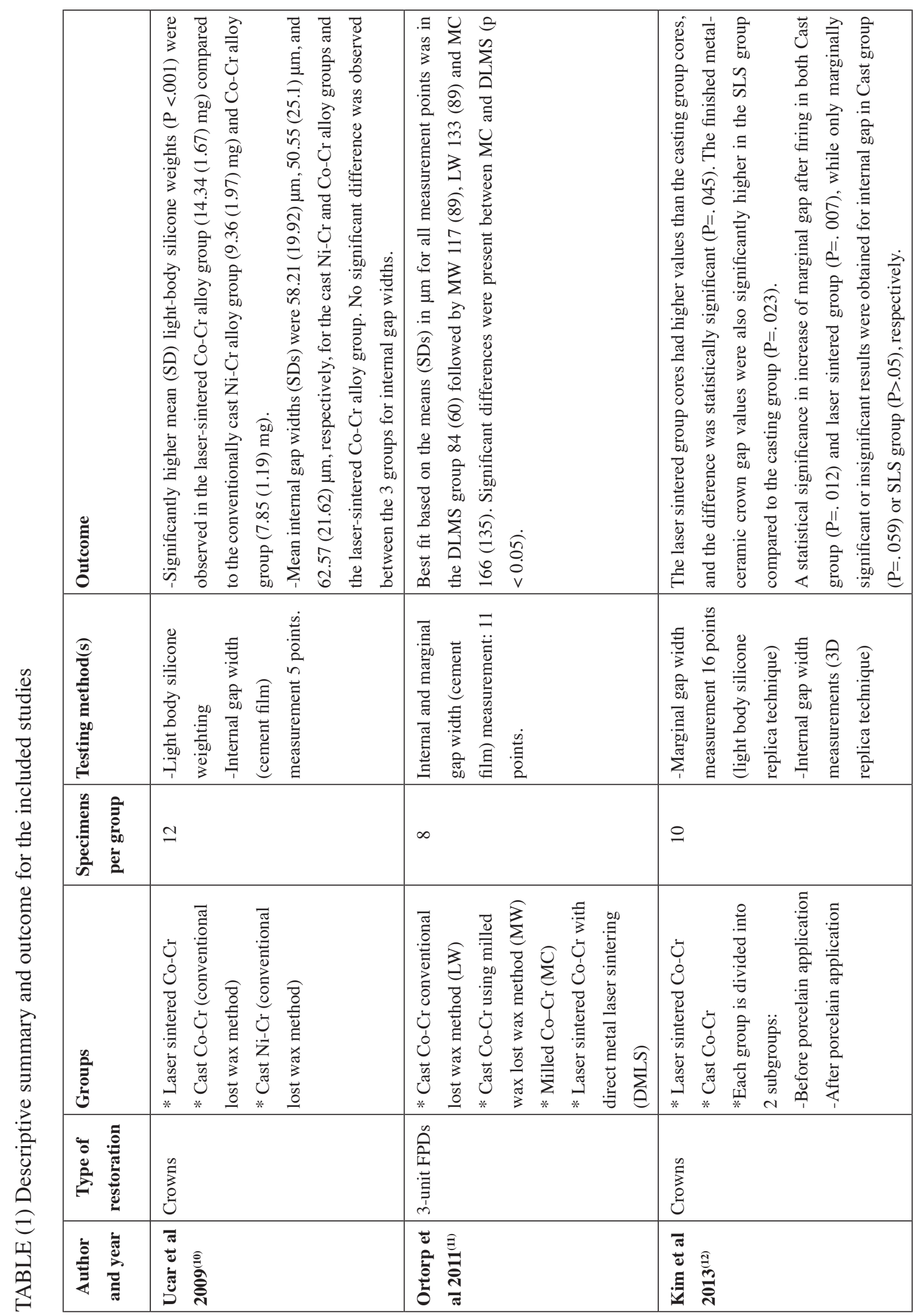




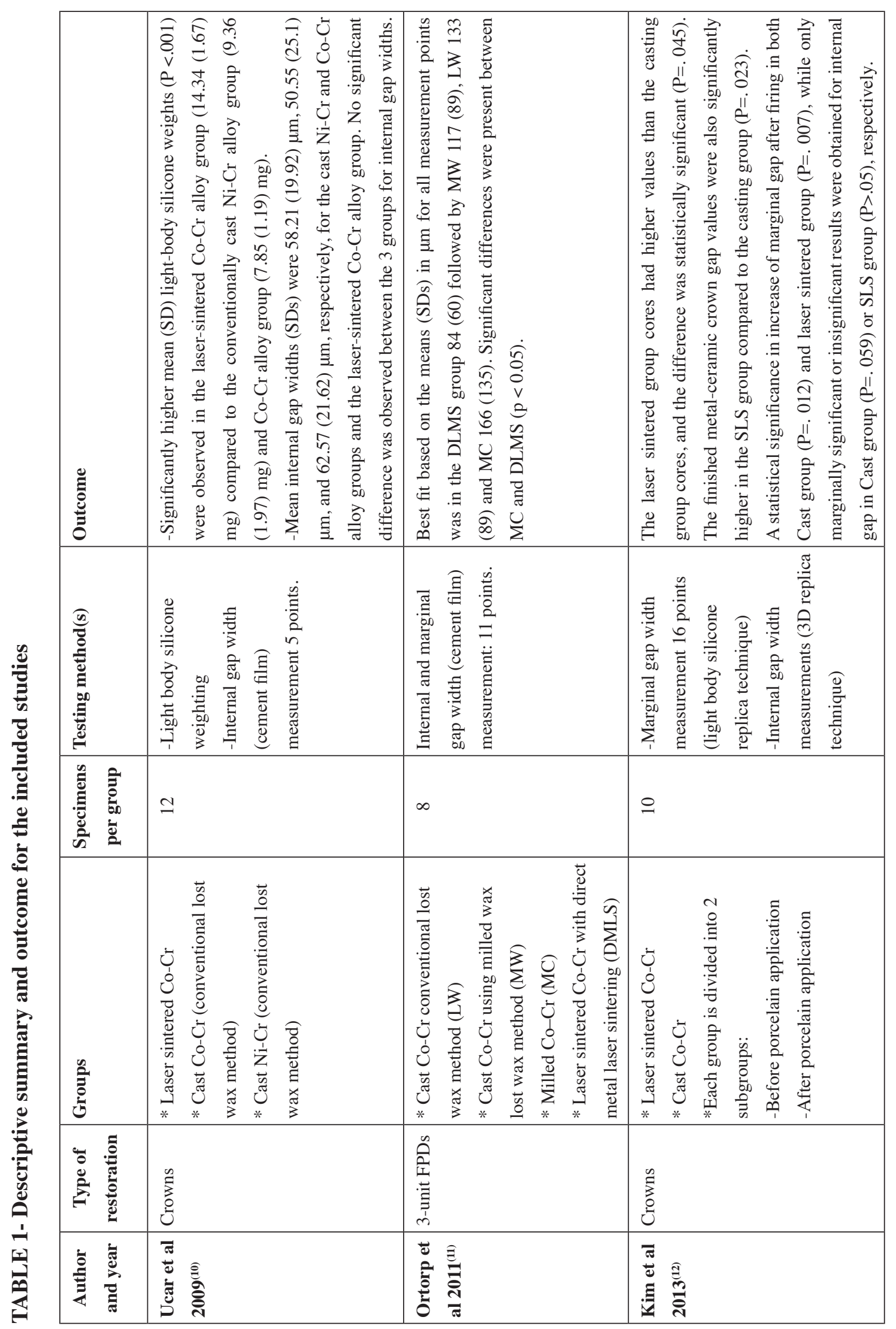




\begin{tabular}{|c|c|c|c|c|}
\hline 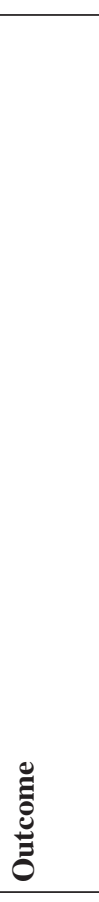 & 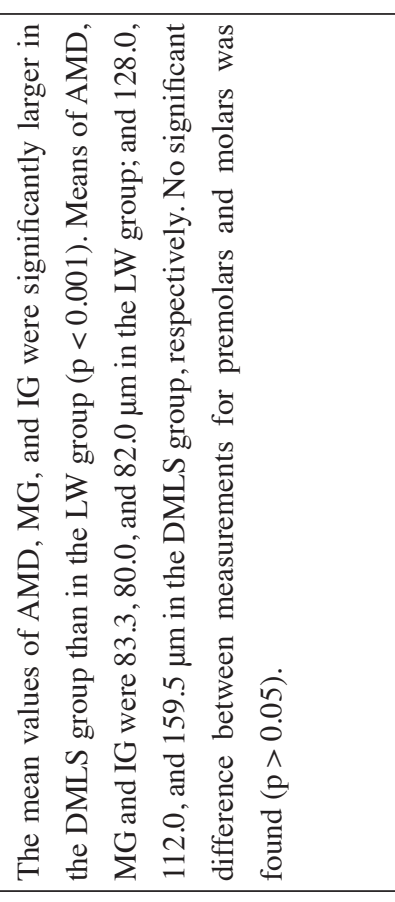 & 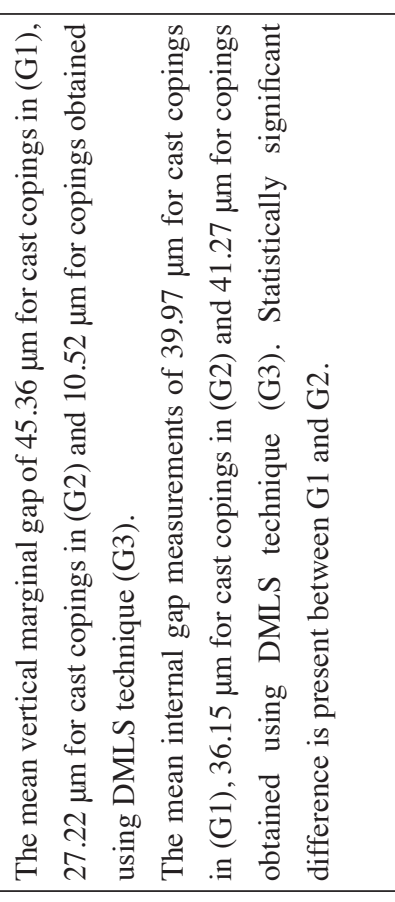 & 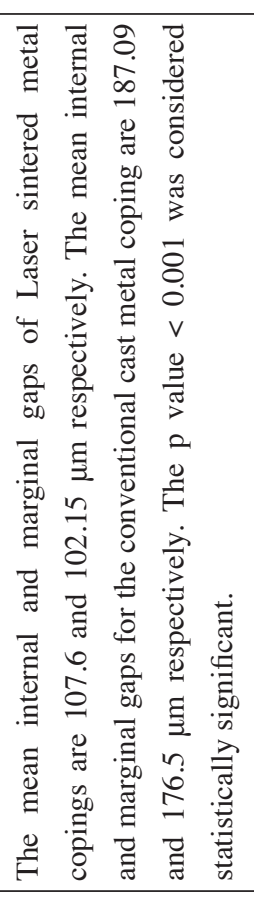 & 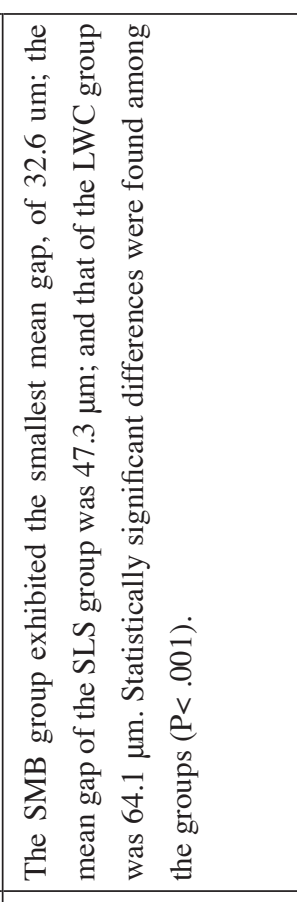 \\
\hline 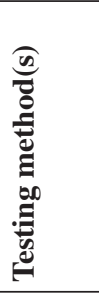 & 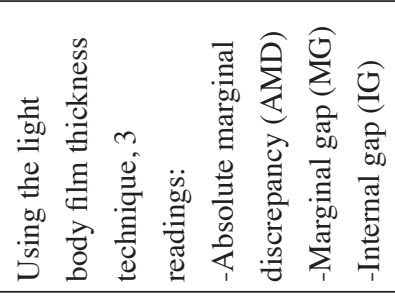 & 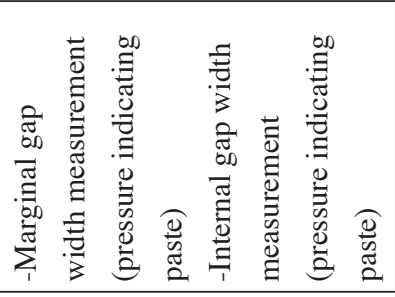 & 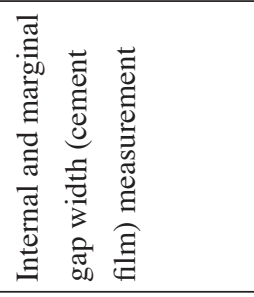 & 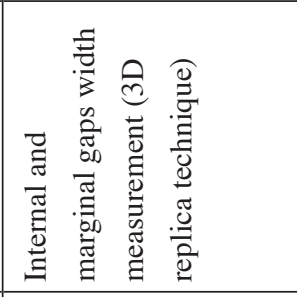 \\
\hline 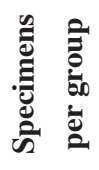 & 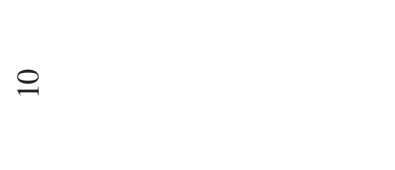 & 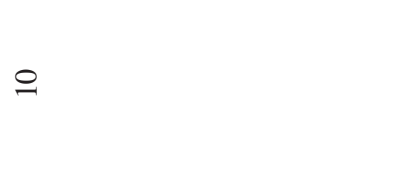 & 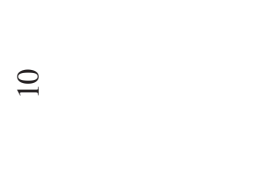 & 으 \\
\hline 号 & 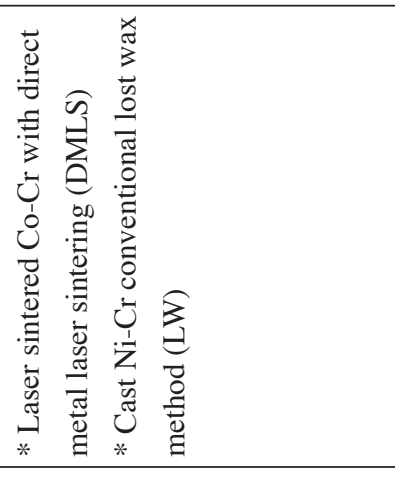 & 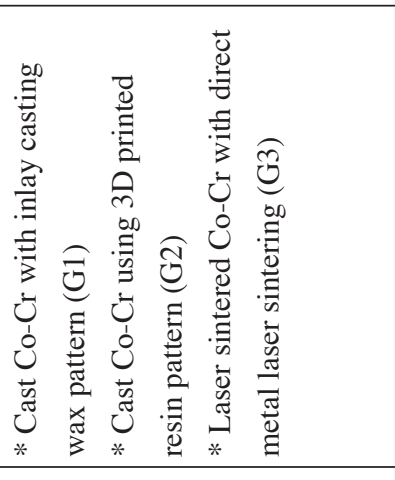 & 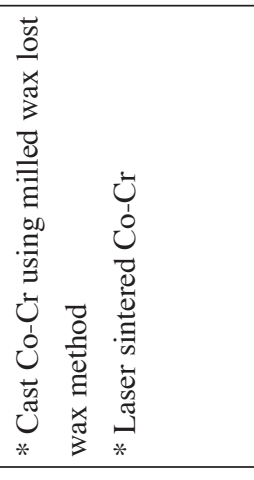 & 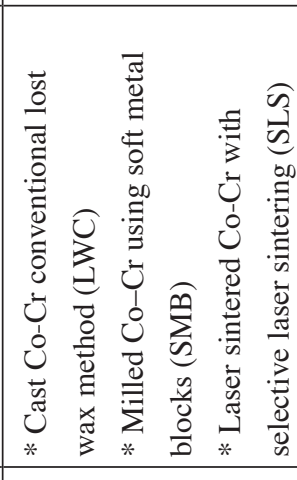 \\
\hline 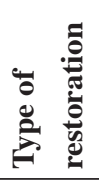 & 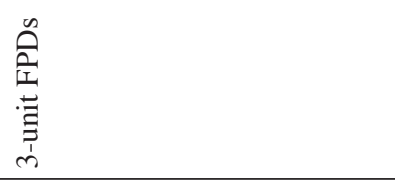 & $\begin{array}{l}0 \\
0 \\
0 \\
0\end{array}$ & $\sum_{0}^{n}$ & $\sum_{0}^{\infty}$ \\
\hline 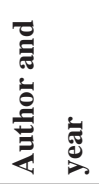 & 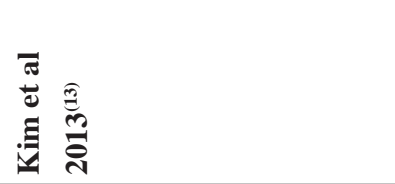 & 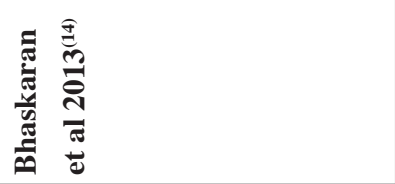 & 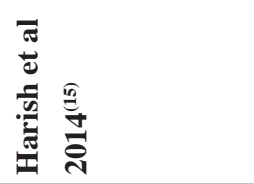 & 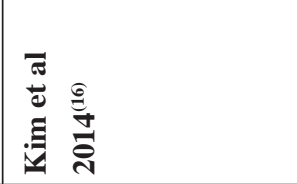 \\
\hline
\end{tabular}




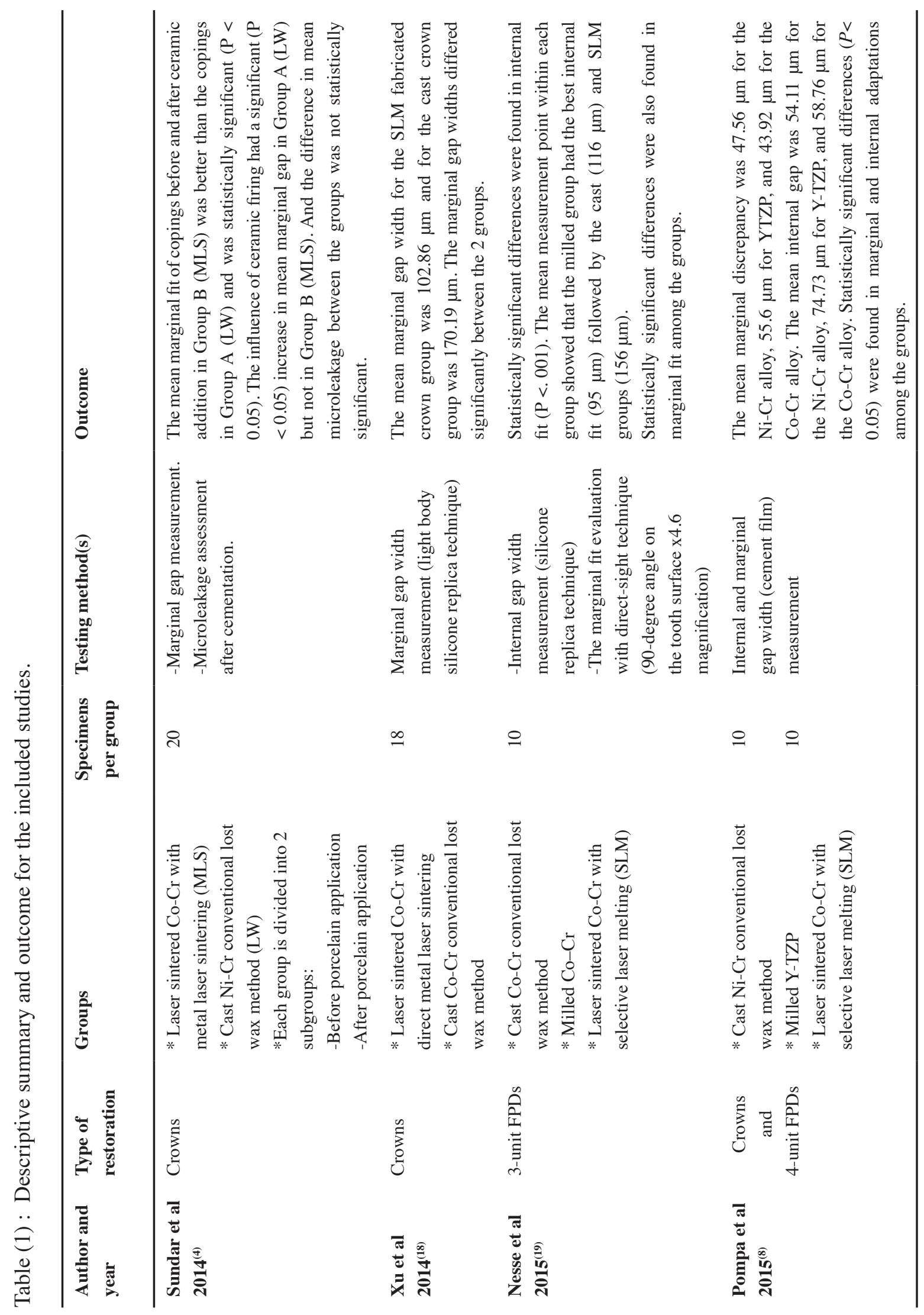




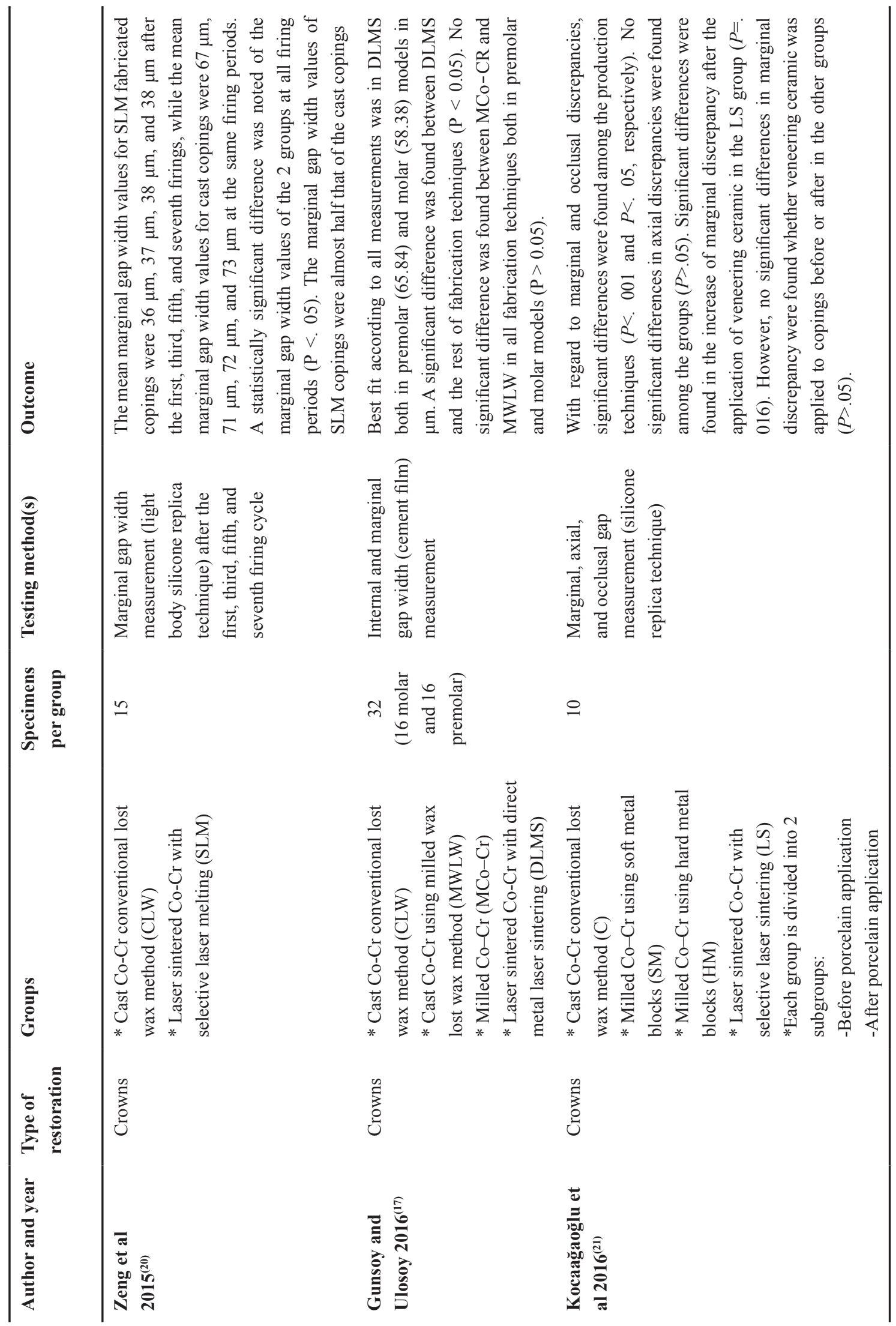




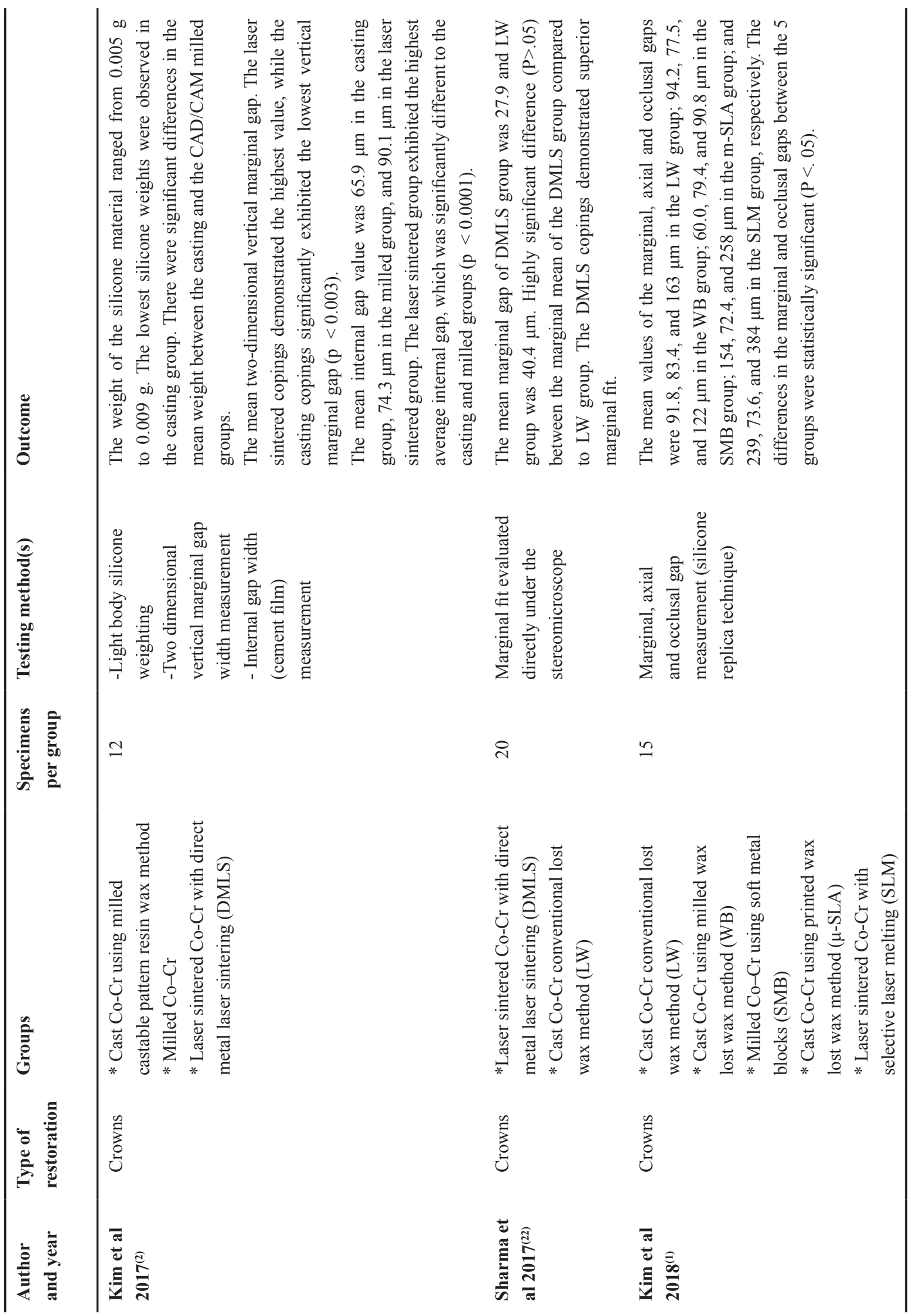




\section{DISCUSSION}

Accurate marginal and internal fit is considered one of the major criteria for clinical success of fixed restorations. Marginal inaccuracies causing plaque retention can cause marginal gingival inflammation, gingival recession and formation of secondary caries below the margins of the crown ${ }^{(23)}$ causing failure of restorations ${ }^{(24)}$. Thus, irrespective of any crown fabrication techniques, the marginal and internal fit of the coping is important for the success of the restoration. ${ }^{(15)}$ Before making any attempt to assess such parameters, the acceptable gap dimensions should be known, however, there is no consensus on the clinically acceptable limits of marginal and internal gaps. According to American Dental Association (ADA) Specification No. 8, a gap width ranging between 25 to $40 \mu \mathrm{m}$ has been suggested as a clinical goal ${ }^{(20)}$. Sulaiman et $\mathrm{al}^{(25)}$ reported that $100 \mu \mathrm{m}$ is an acceptable gap for clinical use. McLean and von Fraunhofer ${ }^{(26)}$ on the other hand have suggested that $120 \mu \mathrm{m}$ should be the limit for clinical use. Moldovan et $\mathrm{al}^{(27)}$ reported that a gap of 200-300 $\mu \mathrm{m}$ is also acceptable. However, several researches consider the value of $120 \mu \mathrm{m}$ proposed by McLean and von Fraunhofer to be the most suitable limit for clinical use.

There was a significant variation between the values obtained by the included studies even for the same system. These variations may be due to difference in fabrication process, difference in scanning technique or even difference in study designs: the shape of the study casts, the types of abutment teeth, and the measurement methods. Because of such variability, it was impossible to rank the available systems in terms of accuracy or to formulate a proper meta-analysis. However, almost all the measurements were well within the clinically acceptable range suggested by McLean and von Fraunhofer. There was an agreement between the studies that the used systems have the ability to yield restorations with a clinically acceptable fit.

\section{Laser sintering versus lost wax}

Nine studies found that laser sintered metal copings had better marginal and internal fit than the casted metal copings while six studies found the opposite. Casting is highly technique-sensitive, requiring qualified technicians, control of the wax pattern fabrication and investing procedure, and careful attention during the casting process. Many procedures are required to execute this process, which increases the possibility of mistakes affecting the accuracy and fit of copings made. According to Harish et al ${ }^{(15)}$, fit accuracy can be compromised by shrinkage and stress relaxation of the inlay casting wax, high setting expansion of investment and high coefficient of thermal expansion of the molten alloy. Also the induction coil heating used melts alloy at higher temperature than its melting range, which may cause the alloy to lose its low melting point compositional elements making it more viscous and affecting its flow.

On the other hand, Laser Sintering of metal copings may avoid the distortions related to casting procedures. The $\mathrm{CAD}$ process of producing copings by laser sintering technique using automated scanning process and powerful CAD software offers many advantages such as complete control over coping thickness and design, margin placement and cement space maintenance as well as elimination of casting procedures. ${ }^{(14)}$ Moreover, rapid solidification of cobalt chrome powder, which occurs in small sections, minimizes the chance of shrinkage of the alloy. ${ }^{(15)}$ Also the composition of the alloy used may affect the final result. Bashkaran et al ${ }^{(14)}$ stated that the composition of $\mathrm{Co}-\mathrm{Cr}$ alloy used for laser sintering has lower molybdenum content compared to $\mathrm{Co}-\mathrm{Cr}$ alloy used for conventional casting. Laser sintering of alloy is facilitated by the absence of such refractory metals that have higher melting range than cobalt and chromium. However, there are three main factors that could affect the fit accuracy of laser sintered metal coping: the precision of the 
scanner that reads the abutments, how the software can transform the scanning data into a 3D model in the computer, and the precision of the machine that will CAM the objects from the CAD data. ${ }^{(10,22)}$

Bashkaran et $\mathrm{al}^{(14)}$ and Pompa et $\mathrm{l}^{\left({ }^{(8)}\right.}$ found mixed results in their studies. Marginal fit was better in the laser sintered groups while internal fit was better in the lost wax groups. According to Bashkaran, this could be because while scanning the master die and constructing three dimensional coping shell model image, the margin determination was done under manual adjustment while the external surface scanning of the master die was determined by the non uniform offsetting and shelling algorithm in the scanning system software which lead to those variable results.

\section{Laser sintering versus milling}

Eight of the selected studies compared laser sintering with $\mathrm{CAD} / \mathrm{CAM}$ milling showing mixed results. Ortorp et $\mathrm{al}^{(11)}$ found that laser sintered frameworks had significantly better marginal fit than milled framework. This was in agreement with Gunsoy and Ulosoy ${ }^{(17)}$ and Pompa et $\mathrm{al}^{\left({ }^{(8)}\right.}$; And in disagreement with Kim et al (2014) ${ }^{(16)}$ and Kim et al $(2018)^{(1)}$. This variability in results can be explained by the two possible factors related to the fit of restorations produced by CAD software: the skill of the technician using the software and the accuracy of the scanning process. According to Ortorp et $\mathrm{al}^{(11)}$ and Kim et $\mathrm{al}^{(2)}$, possible sources of error of the milling technique include the wear of milling instruments when milling such a hard material as $\mathrm{Co}-\mathrm{Cr}$ and a change in the radius of the instruments during the milling procedure, which can reduce the milling precision. A change of the milling instruments at regular intervals is highly recommended in order to control this factor and reduce the risk of using burs with decreased diameters, in case the milling machine lacks the capacity to fully compensate for this phenomenon. Moreover, Vibrations during the milling process and resistance of the milling axis during preparation could also affect the accuracy of the milling procedure.

\section{Effect of methodology}

Several methods have been used to measure the fit accuracy of dental restorations in the selected articles. Among these methods, the Internal microscopic examination after sectioning and the silicone replica approach were used the most. In the Former approach, the specimen is applied to the abutment or model, fixed and cut, and the crosssection is observed using a digital microscope or by scanning electron microscopy. Measurements cannot be made from various points with these methods, and the biggest drawback is that the specimens and models are destroyed. In the silicone replica approach, the gap between the specimen and the abutment or the model is replicated by using light body silicone, and the silicone replica is cut so that the cross-section can be observed with a digital microscope. Although this technique is non-destructive, measurements cannot be made from various points ${ }^{(12)}$. Moreover, precise analysis is not possible since both these methods use 2D measurements and cannot meet the requirement proposed by Groten et $\mathrm{al}^{(28)}$ of measuring the gap at a minimum of 50 points while evaluating the fit.

Two of the selected articles ${ }^{(12,16)}$ used a new measurement method to overcome the limitations of these two earlier methods. These studies measured the gap 3-dimensionally and evaluated the fit by using a computer. This method overcomes the disadvantages of the two earlier methods because it is nondestructive, facilitates easy measurement; and permits measurement in the oral cavity in case of clinical study ${ }^{(16)}$. The accuracy and reliability afforded by 3 -dimensionally analyzing gaps with a computer have been reported by previous studies. ${ }^{(29)}$. When using this method, meeting the requirement of measuring more than 50 points is possible for evaluating the fit of a single tooth. The limitation of this method is that the marginal discrepancy cannot be measured because the margin is not a face but a 
line, and accurate point cloud data are difficult to obtain from the digital replica; therefore it's more suitable to evaluate the internal rather than the marginal fit. ${ }^{(16)}$

\section{CONCLUSIONS}

Laser sintered metal copings have a good marginal and internal fit within the clinically acceptable range suggested in the literature. While further research is necessary to optimize the process parameters and clinical applications, the laser sintering procedure provides an efficient and rapid method for digitally designing and manufacturing complex metal structures for crowns and FPDs.

\section{REFERENCES}

1. Kim D-Y, Kim J-H, Kim H-Y, Kim W-C. Comparison and evaluation of marginal and internal gaps in cobaltchromium alloy copings fabricated using subtractive and additive manufacturing. J Prosthodont Res. 2018;62(1): 56-64.

2. Kim M-J, Choi Y-J, Kim S-K, Heo S-J, Koak J-Y. Marginal Accuracy and Internal Fit of 3-D Printing Laser-Sintered Co-Cr Alloy Copings. Materials. 2017;10(1):93.

3. Venkatesh KV, Nandini VV. Direct metal laser sintering: a digitised metal casting technology. J Indian Prosthodont Soc. 2013;13(4):389-92.

4. Sundar MK, Chikmagalur SB, Pasha F. Marginal fit and microleakage of cast and metal laser sintered copings - An in vitro study. J Prosthodont Res. 2014;58(4):252-8.

5. Foster L. Failed conventional bridge work from general dental practice: clinical aspects and treatment needs of 142 cases. Br Dent J. 1990;168(5):199.

6. Jahangiri L, Wahlers C, Hittelman E, Matheson P. Assessment of sensitivity and specificity of clinical evaluation of cast restoration marginal accuracy compared to stereomicroscopy. J Prosthet Dent. 2005;93(2):138-42.

7. Limkangwalmongkol P, Chiche GJ, Blatz MB. Precision of fit of two margin designs for metal-ceramic crowns. J Prosthodont. 2007;16(4):233-7.

8. Pompa G, Di Carlo S, De Angelis F, Cristalli MP, Annibali S. Comparison of conventional methods and laser- assisted rapid prototyping for manufacturing fixed dental prostheses: an in vitro study. Biomed Res Int. 2015;2015.

9. Moher D, Liberati A, Tetzlaff J, Altman DG, Group P. Preferred reporting items for systematic reviews and meta-analyses: the PRISMA statement. PLoS Med. 2009;6(7):e1000097.

10. Ucar Y, Akova T, Akyil MS, Brantley WA. Internal fit evaluation of crowns prepared using a new dental crown fabrication technique: laser-sintered $\mathrm{Co}-\mathrm{Cr}$ crowns. J Prosthet Dent. 2009;102(4):253-9.

11. Örtorp A, Jönsson D, Mouhsen A, von Steyern PV. The fit of cobalt-chromium three-unit fixed dental prostheses fabricated with four different techniques: A comparative in vitro study. Dent Mater. 2011;27(4):356-63.

12. Kim K-B, Kim J-H, Kim W-C, Kim H-Y, Kim J-H. Evaluation of the marginal and internal gap of metalceramic crown fabricated with a selective laser sintering technology: two-and three-dimensional replica techniques. J Adv Prosthodont. 2013;5(2):179-86.

13. Kim K-B, Kim W-C, Kim H-Y, Kim J-H. An evaluation of marginal fit of three-unit fixed dental prostheses fabricated by direct metal laser sintering system. Dent Mater. 2013;29(7):e91-e6.

14. Bhaskaran E, Azhagarasan N, Miglani S, Ilango T, Krishna GP, Gajapathi B. Comparative Evaluation of Marginal and Internal Gap of Co-Cr Copings Fabricated from Conventional Wax Pattern, 3D Printed Resin Pattern and DMLS Tech: An In Vitro Study. J Indian Prosthodont Soc. 2013;13(3):189-95

15. Harish V, Mohamed Ali S, Jagadesan N, Mohamed Ifthikar SS, Debasish Basak FH. Evaluation of Internal and Marginal Fit of Two Metal Ceramic System-In Vitro Study. J Clin Diagn Res. 2014;8(12):ZC53.

16. Kim K-B, Kim J-H, Kim W-C, Kim J-H. Threedimensional evaluation of gaps associated with fixed dental prostheses fabricated with new technologies. J Prosthet Dent. 2014;112(6):1432-6.

17. Gunsoy S, Ulusoy M. Evaluation of marginal/internal fit of chrome-cobalt crowns: Direct laser metal sintering versus computer-aided design and computer-aided manufacturing. Niger J Clin Pract. 2016;19(5):636-44.

18. Xu D, Xiang N, Wei B. The marginal fit of selective laser melting-fabricated metal crowns: An in vitro study. J Prosthet Dent. 2014;112(6):1437-40. 
19. Nesse H, Ulstein DMÅ, Vaage MM, Øilo M. Internal and marginal fit of cobalt-chromium fixed dental prostheses fabricated with 3 different techniques. J Prosthet Dent. 2015;114(5):686-92.

20. Zeng L, Zhang Y, Liu Z, Wei B. Effects of repeated firing on the marginal accuracy of $\mathrm{Co}-\mathrm{Cr}$ copings fabricated by selective laser melting. J Prosthet Dent. 2015;113(2):135-9.

21. Kocaağaoğlu H, Kılınç Hİ, Albayrak H, Kara M. In vitro evaluation of marginal, axial, and occlusal discrepancies in metal ceramic restorations produced with new technologies. J Prosthet Dent. 2016;116(3):368-74.

22. Sharma M, Bansal A, Panthi S, Malik SS, Sharma A. o evaluate the marginal fit of metal copings fabricated by conventional casting procedure and direct metal laser sintering technology-an in vitro study. Dental Journal of Advance Studies. 2017;5(1).

23. Felton D, Kanoy B, Bayne Sa, Wirthman G. Effect of in vivo crown margin discrepancies on periodontal health. $\mathrm{J}$ Prosthet Dent. 1991;65(3):357-64.
24. Ito M, Kuroiwa A, Nagasawa S, Yoshida T, Yagasaki H, Oshida Y. Effect of wax melting range and investment liquid concentration on the accuracy of a three-quarter crown casting. J Prosthet Dent. 2002;87(1):57-61.

25. Sulaiman F, Chai J, Wozniak WT. A comparison of the marginal fit of In-Ceram, IPS Empress, and Procera crowns. Int J Prosthodont. 1997;10(5).

26. McLean J. The estimation of cement film thickness by an in vivo technique. Br Dent J. 1971;131:107-11.

27. Moldovan O, Rudolph H, Quaas S, Bornemann G, Luthardt R. Internal and external fit of CAM-made zirconia bridge frameworks-a pilotstudy. Dtsch Zahnarztl Z. 2006;61(1):38

28. Groten M,Axmann D, Pröbster L, Weber H. Determination of the minimum number of marginal gap measurements required for practical in vitro testing. $\mathrm{J}$ Prosthet Dent. 2000;83(1):40-9.

29. Luthardt RG, Kühmstedt P, Walter MH. A new method for the computer-aided evaluation of three-dimensional changes in gypsum materials. Dent Mater. 2003;19(1):19-24 